مجلة جامعة الملك عبدالعزيز: الاقتصاد الإسلامي، م31 ع3، ص ص: 115-122 (محرم 1440/ أكتوبر 2018) DOI: 10.4197 / Islec. 31-3.7

\title{
وقفات مع مقال "نحو دورٍ فاعلٍ للأوقاف في حياة المجتمعات المسلمة المعاصرة" للأستاذ الدكتور محمد موفق الأرناؤوط
}

$$
\begin{aligned}
& \text { قراءة وتعليق: العياشي فداد } \\
& \text { كبير الاقتصياديين } \\
& \text { المعهل الإسلامي للبحوث والتدليب - مجموعة البنك الإسلامي للتنمية } \\
& \text { جلة - المملكة العببية السعودية }
\end{aligned}
$$

المستخلص. تناقش هذه المداخلة ما ورد من أفكار وطروحات في ورقة "نحو دور فاعل للأوقاف

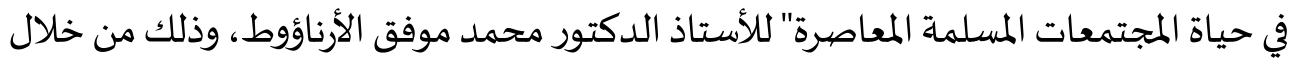

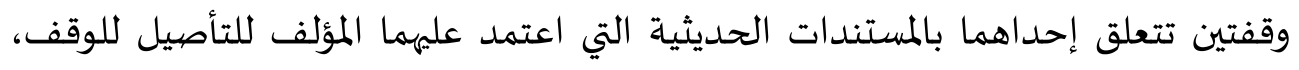

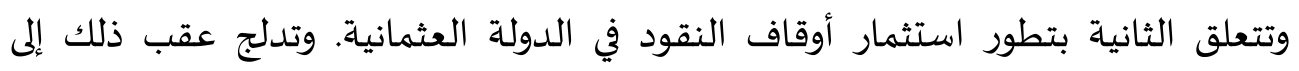
استعراض محاور أخرى في الورقة.

الكلمات الدَّالة: الوقف، وقف النقود، استثمار أوقاف النقود، دور مؤسسة الوقف الحضاري، تجارب ناجحة في الأوقاف.

ت22, E23:KAUJIE تصنيف 


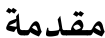

وفي هذا السياق أورد ابن عبد البر، في الاستذكار (ج8،

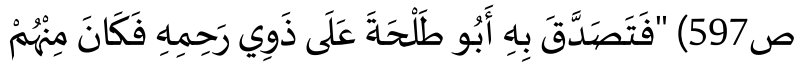

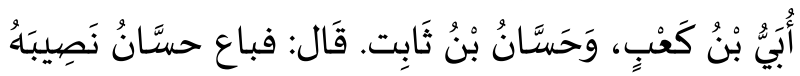

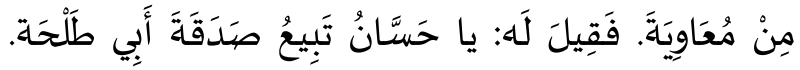

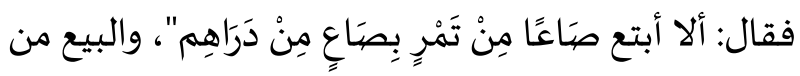

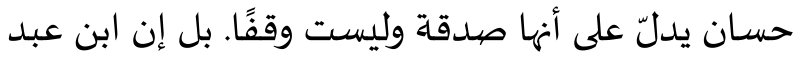
البر يرى أن الأغلب والأظهر من قوله: فقسمها هو "صدقة إنة

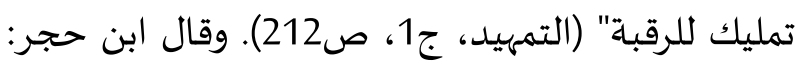

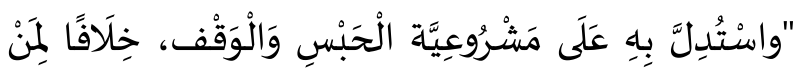

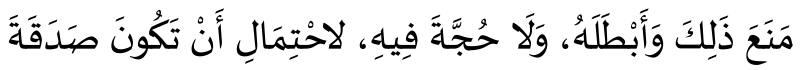

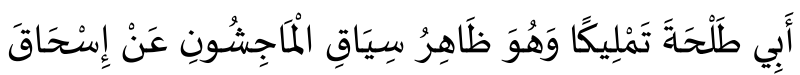

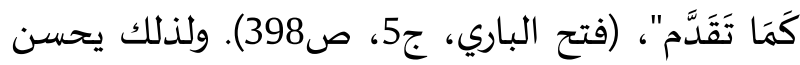

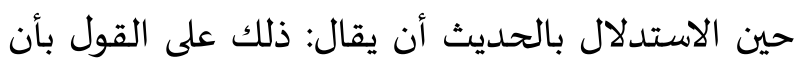
المراد هو الصدقة الجارية، وليس صدقة تمليك الرقبة. 2. الوقفة الثانية: تتعلق بتطور استثمار أوقاف النقود في الدولة العثمانية وبالتحديد عند فقهاء الحنفية المتأخرين. ولابد من التاكيد في هذا المقام على أن الباحث

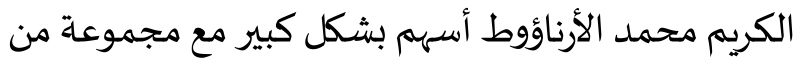
الباحثين الآخرين في إبراز تطور وقف النقود إبان الخلافة

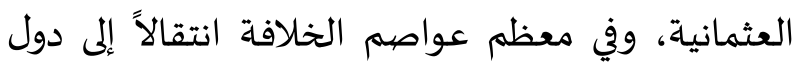

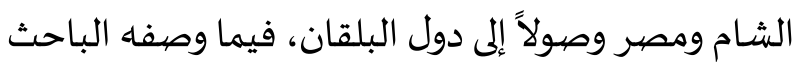

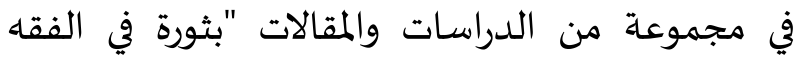

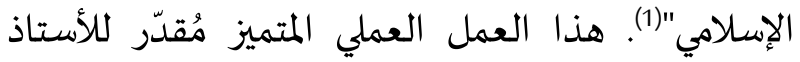
الكريم والباحثين الآخرين. لكن أستأذنه في وقفة فقهية لم

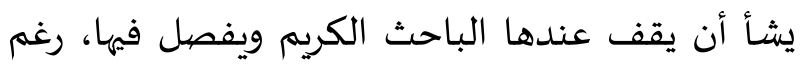
خطورتها. وصدق حين وصفها ب"الثورة الفقهية".

(1) انظر على سبيل المثال: الأرناؤوط، محمد، مقدمة كتاب دراسات في وقف النقود مفهوم مغاير للربا في المجتمع العثماني ، (2001م). ط1 المان، تونس: مؤسسة التميمي.
الورقة في منظورها العام تقدم رؤية شمولية للوقف؛

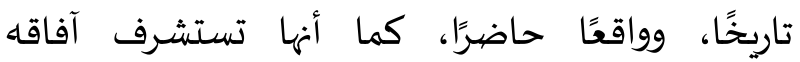
المستقبلية. عارضة لأهم الأدوات التي يمكن العناية بها

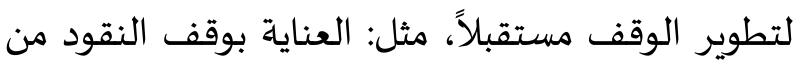
ناحية الاجتهاد الفقهي، والاستفادة من التطبيقات التاريخية التهاية إبان ازدهار الوقف النقدي في أرجاء الدولة العثمانية

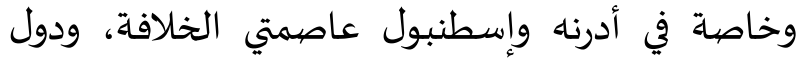

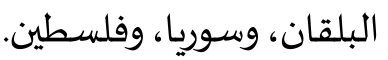
وممّا يحمد للورقة، الصورة المشرقة التي يخرج بها قارئها عن الوقف، ودوره الفاعل في المجتمعات الإسلامية، بل

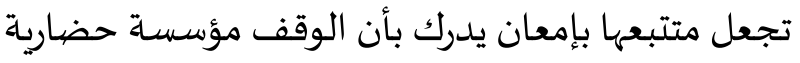
أسهمت في معظم المجالات المتعلقة بحياة الناس: العلمية،

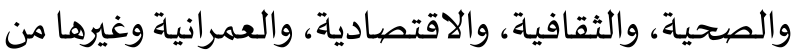
المجالات الأخرى، وذلك بأسلوب رشيق سهل الهضيم والفهم، يقرّب الأهداف والمعاني لكل قارئ.

وأقف مع الباحث وقفتين قبل عرض محاور الورقة

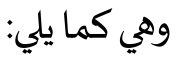
1. أكد الباحث الكريم على أن الوقف استند على ثلاثة

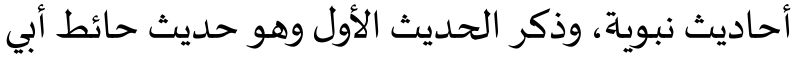
طلحة الأنصاري المسبى بيرحاء، حيث أرشد النبي صلى الله الها

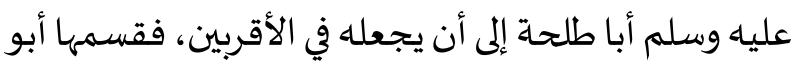
طلحة في أقاربه. والحديث أخرجها مسلم وغيره (صحيح المانح

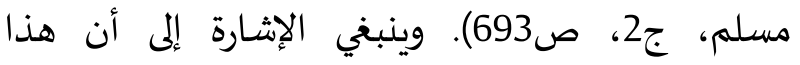

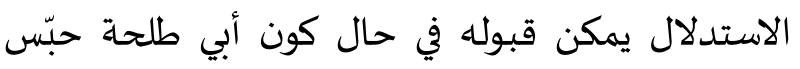

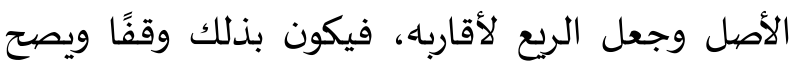

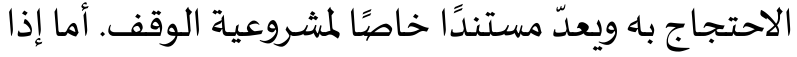
قسمها أبو طلحة فعلاً فتكون صدقة على الأقارب. 
بفائدة يتم توزيعها حسب شرط الواقف على منح للطلبة

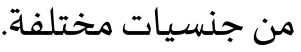

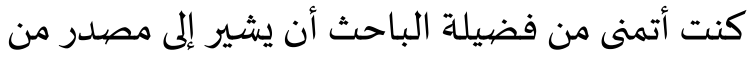

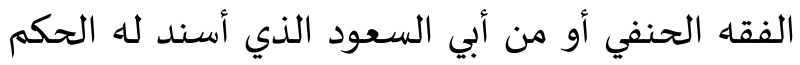
الذي يجيز الاستثمار بفائدة ربوية سنوية.

ومن خلال بحثي المتواضع رجعت للمراجع المتاحة لأبي السعود وخاصة رسالته المشهورة في جواز وقف النقات النقود (2)، وأبواب في التفسير، وبعض الأحكام القضائية المعروضية

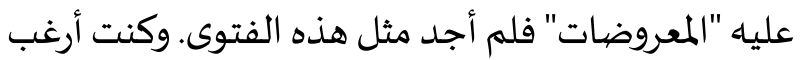

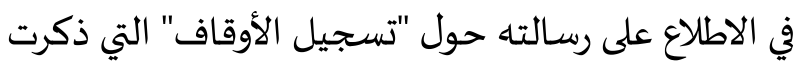
في بعض المصادر، لكنني لم أتمكن من الحصول عليها. وغاية ما يمكن الاستئناس باه من فقه الحنفية في هذا

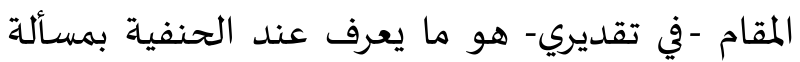

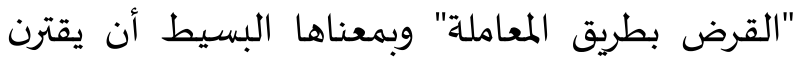

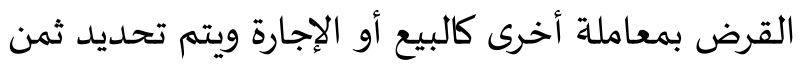

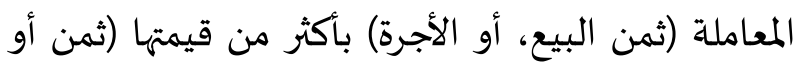

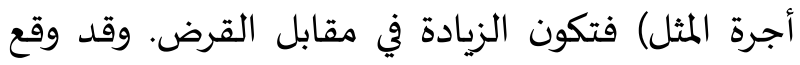

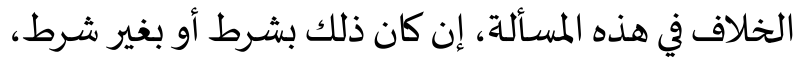
وهل كان القرض قبل المعاملة أو بعده. ويمكن مراجعة إندان

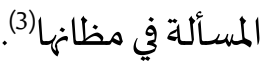

ولكن رغم تقديرنا لمن رأى الجواز فإن هذه المسألة

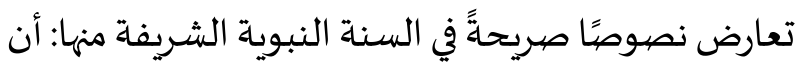
النبي صلى الله عليه وسلم (نهى عن بيع وسلف)(4)،

(2) للاطلاع على رأي أبي السعود تفصيلا راجع: رسالة في جواز وقف

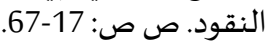

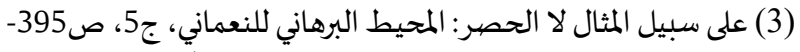

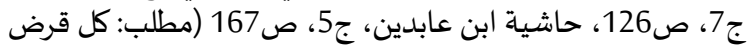

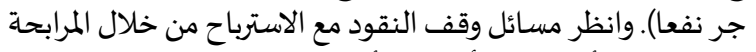

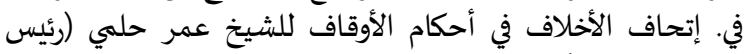

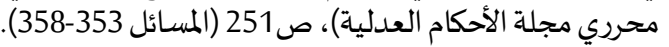

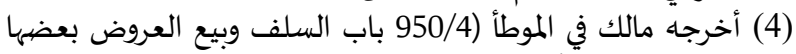
ببعض)، ورواه أصحاب السنن والمسانيد. قال الشئ الشيخ الألباني في

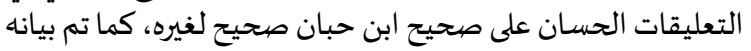

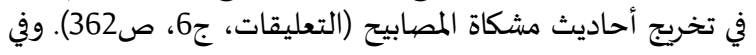

أوافق الأستاذ الكريم على اعتبار أن الراجح والمفتى باه عند متأخري المذهب الحنفي وهو جواز وقف النقود،

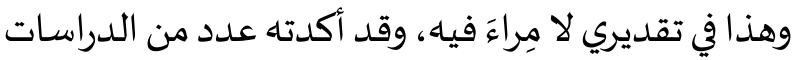
والمقالات التي خصصت لتحقيق المذهب الحنفي في وقف النقود وهو ما لخصيه شيخ الإسلام أبي السعود في رسالته المشهورة. وقد أكد هؤلاء الفقهاء وغيرهم وكذلك من أجاز وقف النقود من المذاهب الأخرى، على أن هذا الوقف همهئ يمكن استثماره بأحد أسلوبين: - القرض الحسن للمحتاجين، على أن يعيد المقترض أصل القرض عند انتهاء أجلها.

- استثماره بصيغة المضاربة أو أي صيغة مشابهة وفق الضوابط الشرعياة، ويحصل الوقف على نسبة من

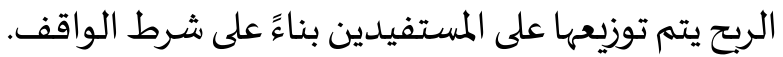

وما لم أتمكّن من فهماه هو ربط الباحث بين ترجيح جواز وقف النقود واستثماره في الإقراض بنسبة فائدة ثابتة على ما جرت عليه التطبيقات آنذاك. ورغم تسليهي

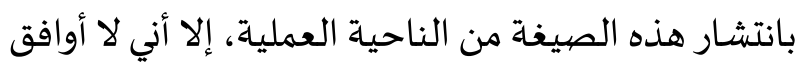
الباحث الكريم في إسناد ذلك إلى أبي السعود رحماه الله. يقول الباحث (ص4) "ووصل الأمر بشيوخ الإسلام في

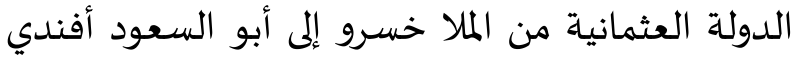

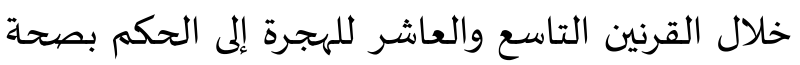

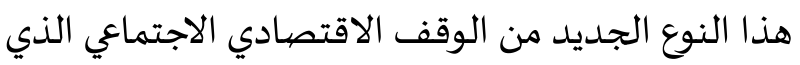

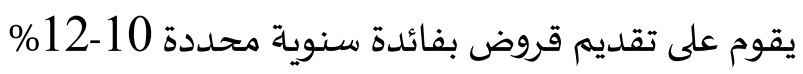
سنويًا لحرفيين وتجار...". وفي التجارب العملية ظهر البحث متأثرًا بهذا الرأي حيث ذكر من ضمن التجارب الملهمة (ص14) الوقفيات التسعة للدكتور محمد شوقي الفنجري في مصر، وبعن العضها كان عبارة عن استثمار لأصل الوقف النقدي في سندات 
ولعلّ من الإشـارات اللطيفة التي أشـارت إلهها الورقة، دور الوقف في المجال العمراني. وقد قدم لنا الباحث أمثلة رائعة من دول البلقان تشهد بها عين الزائر لتلك المناطق.

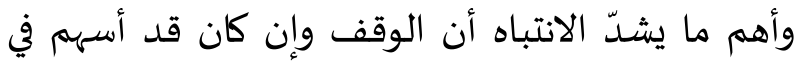
التطور العمراني بشكل غير مباشر إلا أنه ترك أثرًا مهمًا في التخطيط العمراني للمدن وهندستها. فكان الوقف حين إنشائه في المدينة يستتبع ذلك مرافق مهمة مثل: المسجد، والمدرسة، والمصحةة، والمكتبة، ومرافق الراحة والخدماة، وسريعًا ما كانت تحدث تجمعات بشرية تنشئ أوقافًا

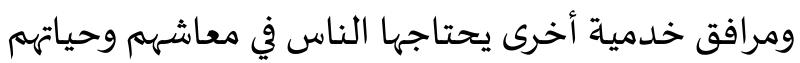
العامة فتتشكل بها ملامح المدينة الجديدة. وقد قدم الباحث الكريم بشكل مفصل نموذجًا رائعًا لتأثير الوقف في تطور العمران وهو نموذج "سراييفو" عاصيمة البوسنة)(7).

2. مستجدات مهمّة في الوقف: وهي من المحاور الجيدة التي ينبغي الاعتناء بها في بحوثنا ومؤتمراتنا، ولا إخال إلا أن ذلك قائم، لكن ينبغي الاجتهاد في تطوير البحث في هذه المستجدات، سواء من الناحية الشرعية، أو الاقتصادياة، أو الاجتماعية مع العناية أكثر فأكثر

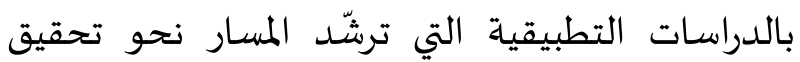
مؤسسات الأوقاف لأهدافها وتحقيق المقاصد العليا للوقف. وقد أبلى الباحث بلاءً حسنًا في الإشـارات الموجزة لتلك

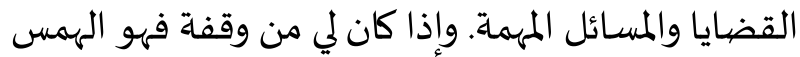
بأن الإرصاد لم يبدأ بفتوى ابن عصرون (585هـ) ليعتبر

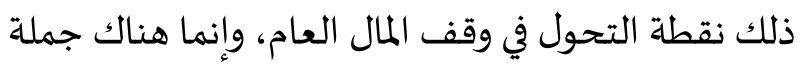

(7) دور الوقف في نشوء المدن الجديدة "سراييفو نموذجا"، مجلة

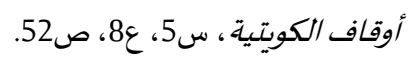

وتعارض القاعدة المتفق عليها والتي تلقاها الفقهاء بالقبول عبر العصور: "كل قرض جرّ نفعا فهو ربا" (5). وشتان بين هذه المسألة التي وقع الخلاف فيها، وردها كثير من محققي المذهب، وأجازها من أجازها لتكون مخرجًا عن الوقوع في شبهة الربا، وبين مسألتنا التي تعتبر

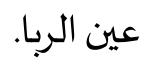
وشملت ورقة العمل محاور مهمة انبرى لها الباحث الكريم وعرضها فأحسن في عرضها والكشف عن مكنوناتها.

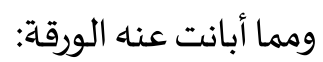

\section{1. دور مؤسسة الوقف الحضباري في المجالات:} الثقافية، والتعليمية، والاجتماعية. وكان هذا المحور محل الم اهتمام العديد من الباحثين والدارسين منذ أن أبرزه مصطفى السباعي (1384هـ/1964م) في كتابه من روائع حضيارتنا (6). بل ثمة دراسات وإسهامات في هذا المحور قبله

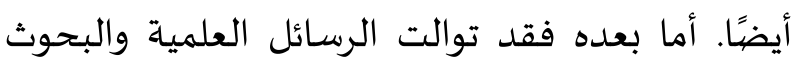
والدراسات وعقد المؤتمرات والندوات في الموضوع، لتعلن عن صحوة علمية للوقف وإبراز لدوره الفاعل في ثقافة الأمة، وإقامة صروحاه العلمياة، والصحية، والاجتماعية. وقد أبانت عن ذلك كله الورقة أيما بيان معززة ذلك بنماذج من الأوقاف الرائدة في العالم الإسلامي.

السلسلة الصحيحة أكد على أن إسناده من ذلك الطريق جيد، ثم

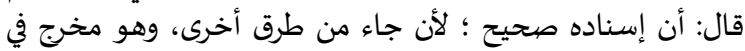
"أحاديث البيوع"، و"المشكاة" و"إرواء الغليل" (انظر : سلسلة الأحاديث

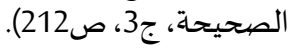

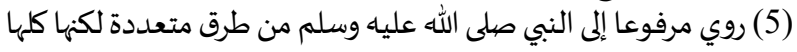

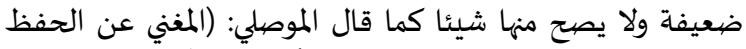

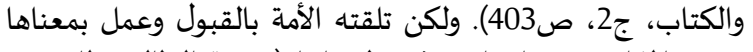

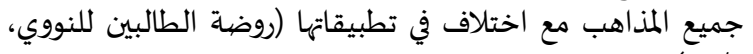

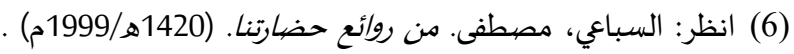
ط1، بيروت: دار الوراق، ص ص صن 93-268. 
خلال مؤتمر وزراء أوقاف الدول الإسلامية، لكن مع كل تلك الجهود وغيرها نحن في أمس الحاجة للتنويع في تشريعات الأوقاف من ناحية، ومن ناحية أخرى أن تعمل

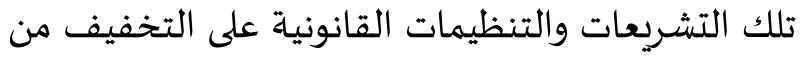
سلطة يد الدولة على الأوقاف، لتصبح الدولة رقيبًا وحارسًا

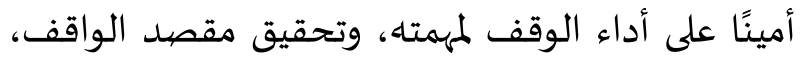

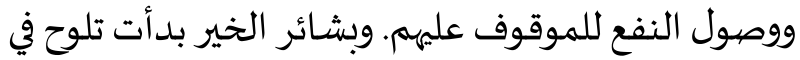
الأفق من خلال إنشاء هيئات ودواوين عامة للأوقاف

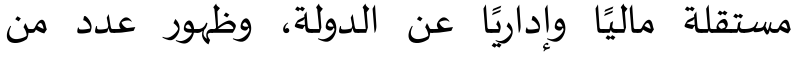

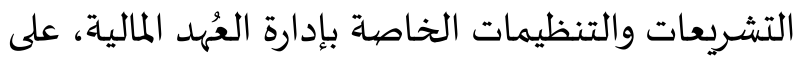

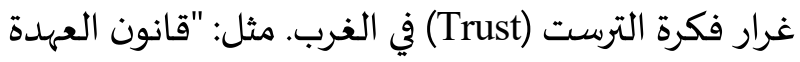
المالية" الصادر عن البنك المركزي في البحرين، وقانون

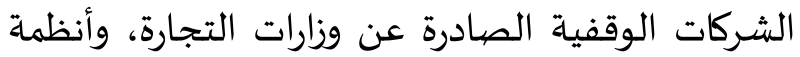
الصناديق الاستثمارية الوقفية الصادرة عن سوق الأوراق

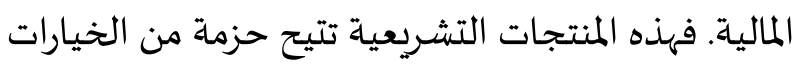

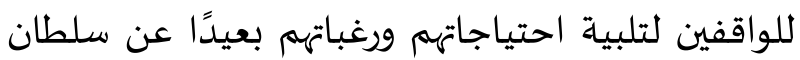

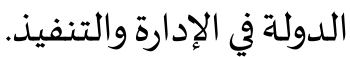

ثم إن هذه الأنظمة المتعددة بمنتجاتها في الواقع

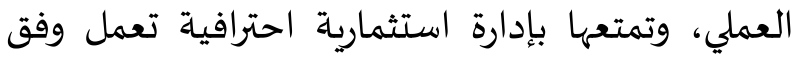
شروط السوق، وتستظل بحوكمة متطابقة مع المعايير الدولية. كل ذلك يُسهم في إعادة الثقة بمؤسسة الوقف ويشجع على الإقبال على الوقف من كافة شرائح المجتمع. وأخيرًا وليس آخرًا في دور الوقف من الناحية الاقتصادية فإن ثمة عدد من المؤسسات قد أصدرت تقارير مالية تتعلق بشؤون الوقف من حيث قطاعاته، وموجوداته، وأصوله المالية، وإسهامه في الناتج المحلي للدولة، فالتحدي أمام الباحثين مستقبلاً هو كيفية الاستفادة من نتائج هذه التقارير للوصول إلى موجهات التاحئ إرشادية على المستوى الكلي حتى تتكامل النظرة الاقتصادية للوقف لتعنى بالمستويين الجزئي والكلي معا.
من الآراء والفتاوى في مختلف المذاهب الفقهية سبقت ابن عصرون وكان لها الأثر في ظهور العديد من التطبيقات. (راجع: بحوث منتدى قضايا الوقف الفقهية الثامن، الموضوع الأول: وقف المال العام). 3. التجارب الناجحة: قدم الباحث نماذج رائعة من ألمات ألمات أوقاف معاصرة تسهم في تلبية حاجات المجتمع، ويمكن أن

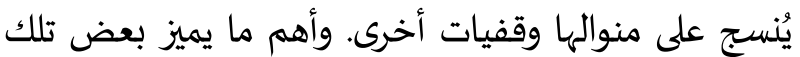
المشاريع هو تفعيل الشراكة بين القطاع الخاص والعام مما سيحدث نقلة نوعية (Public-Private Partnership-PPP) في استثمار الأوقاف إذا ما أحسن الاستفادة من تلك التجارب. لكن يبقى أن البحث لم يغص في تجارب أخرى معاصرة رائدة وخاصاة تلك التي يقوم القطاع الخاص بدور فاعل فيها. مثل: أوقاف الشيخ سليمان الراجي التي تزبد عن 60 مليار ريال سعودي. وكذلك تجربة الصناديق الوقفية الاستثمارية وعلى رأسها المحافظ الوقفية العقارية لجامعاة الملك سعود بالرياض، والصناديق الاستثمارية الوقفية في بعض البنوك مثل بنك الإنماء، والشركات الوقفية وغيرها

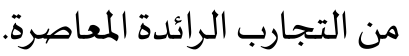

4. المعوقات: أجاد الباحث الكريم وأفاد في ذكر العديد من المعوقات التي تكبّل الأوقاف، وتحتاج إلى الى تضافر الجهود، جهود: الجامعات ومراكز البحث العلمي، وإدارات وهيئات الأوقاف، والقطاع الخاص، والقطاع القاع القادئ العام بكافة هيئاته ذات العلاقة. ومن أهم التحديات التي أشار إلهها الباحث الكريم،

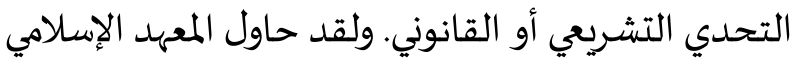
للبحوث والتدربب عضو مجموعة البنك الإسلامي للتنمية بالتعاون مع الأمانة العامة للأوقاف بدولة الكويت إعداد قانون نموذجي استرشادي للأوقاف يمكن على أساسه إعداد قوانين أو تطوير قوانين قائمة، أرفقه بمدكرة

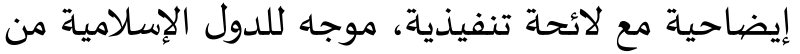




$$
\text { هناك من محسنات فيما تم تقديماه. }
$$

ابن عبدالبر، أبو عمر يوسف بن عبد الله بن محمد. (1421هـ/

2000م). الاستذكار. ط1، بيروت: دار الكتب لعلمية.

عمر حلمي، إتحاف الأخلاف في أحكام الأوقاف. عربه عن اللغة

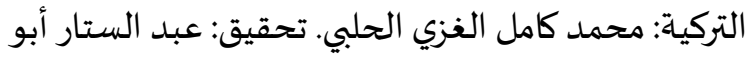
غدة. ط1، جدة: منشورات دلة البركة.

ابن مازة البخاري، أبو المعالي برهان الدين محمود بن أحمد بن

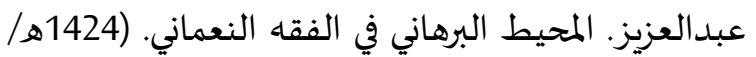
2004م). تحقيق: عبد الكريم سامي الجندي، ط1، بيروت:

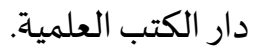

مالك بن أنس، موطأ الإمام مالك. (1406هـ/1985م). صحححه ورقماه وخرج أحاديثه وعلق عليه: محمد فؤاد عبد الباقي.

$$
\text { د.ط، بيروت: دار إحياء التراث العربي. }
$$

مسلم، أبو الحسن بن الحجاج القشيري. صحيح مسلم المسيى المسي

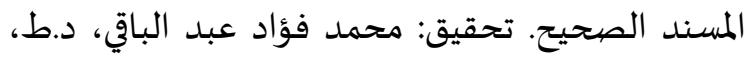

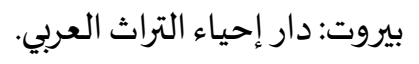

المعهد الإسلامي للبحوث والتدريب بجدة، الأمانة العامة

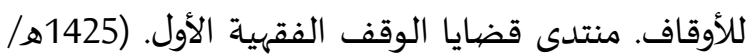

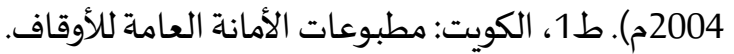

الموصلي، أبو حفص ضياء الدين عمر بن بدر بن سعيد. المغني عن الحفظ والكتاب، مطبوع مع جنة المرتاب بنقد المغني عن الحفظ والكتاب لأبي إسحاق الحويني). (1407هـ). ط1، بيروت: دار الكتاب العربي - بيروت.

\section{Translation of Arabic References}

al-Arna'ut, Muhammad Muwaffaq. (2005). Dawr alWaqf fi Nushoo' al-Mudun al-Jadeedah fi al-Bosnah: Sarayeevoh Namuzajan (The role of Waqf in the Emergence of New Cities in Bosnia: Sarajevo as a Model). Awqaf Journal, The General Secretariat of Endowments, No. 8 (Kuwait 2005), p. 52.

al-Albani, Muhammad Nasir al-Din. (1424H/2003). alTa'leeqat al-Hisan 'Ala Sahih Ibn Hibban (The
أكرر شكري وتقديري للباحث الكريم وما ذكرت لا ينقص من قيمة البحث شيئًا، وهو يرهي لتحسينا إذا كان المراجع

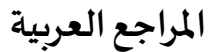

الأرناؤوط، محمد موفق. دور الوقف في نشوء المدن الجديدة "سراييفو نموذجا"، الأمانة العامة للأوقاف، مجلة أوقاف.

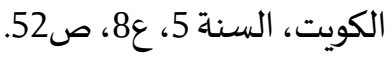

الألباني، محمد ناصر الدين. التعليقات الحسان على صحيح ابن حبان. (1424هـ/2003م). ط1، جدة: دار باوزير.

الألباني، محمد ناصر الدين. سلسلة الأحاديث الصحيحة. (1415هـ/1995م). ط1، الرياض: مكتبة المعارف. لماضئ. ابن حجر العسقلاني، أبو الفضل أحمد بن علي، فتح الباري

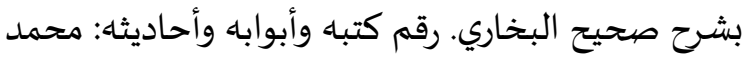

$$
\text { فؤاد عبد الباقي، بيروت: دار المعرفة. }
$$

أبو السعود، محمد بن محمد العمادي، رسالة في جواز وقف النقود. (1417هـ/1997م). تحقيق: أبو الأشبال صغير

$$
\text { أحمد. ط1، بيروت: دار ابن حزم. }
$$

ابن عابدين، محمد أمين بن عمر. رد المحتار على الدر المختار

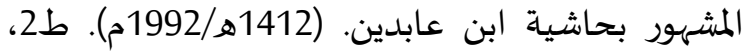

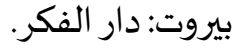

ابن عبدالبر، أبو عمر يوسف بن عبد الله بن محمد. (1387هـ). التمهيد لما في الموطأ من المعاني والأسانيد. تحقيق مصطفى بن بن أحمد العلوي و محمد عبد الكبير البكري، د. ط، المغرب: وزارة عموم الأوقاف والشؤون الإسلامية.

Beautiful Comments on the Compilation of Authentic Ahadith by Ibn Hibban). Jeddah, KSA: Dar BaWazir.

al-Albani, Muhammad Nasir al-Din. (1415H/1995). Silsilat al-Ahadith al-Saheehah (The Series on Authentic Ahadith). Riyadh, KSA: Maktabat alMa'arif.

Ibn Hajar al-'Asqalaani, Abu al-Fadal Ahmad bin Ali. (n.d.). Fath al-Bari bi Sharh Sahih al-Bukhari 
(Inspirations from the Creator in Explaining the Authentic Narrations by al-Bukhari). Muhammad Fu'ad Abdul Baqi (Ed.). Beirut, Lebanon: Dar alMa'rifah.

Abu al-Sa'ud, Muhammad bin Muhammad al-'Imadi. (1417H/1997). Risalah fi Jawaz Waqf al-Nuqud (A Treatise on the Permissibility of Cash Waqf). Abu alAshbaal Saghir (Ed.). Beirut, Lebanon: Dar Ibn Hazm.

Ibn Abideen, Muhammad bin Umar. (1412H/1992). Radd alMuhtar 'Ala al-Durr al-Mukhtar - Hashiyat Ibn Abideen (Directing the Puzzled One to the Meanings of the Chosen Gem - Ibn Abideen's Commentary). Beirut, Lebanon: Dar al-Fikr.

Ibn Abdul Barr, Abu Umar Yusuf bin Abdullah bin Muhammad. (1387H). al-Tamhid li ma fi al-Mu'atta min al-Ma'ani wa al-Asaneed (The Introduction to alMu'atta, its Meanings and Narrations). Mustafa bin Ahmad al-'Alawi \& Muhammad Abdul Kabeer alBakri (Eds.). Morocco: Ministry of Awqaf \& Islamic Affairs.

Ibn Abdul Barr, Abu Umar Yusuf bin Abdullah bin Muhammad. (1421H/2000). al-Istizkaar (The Recollection). Beirut, Lebanon: Dar al-Kutub al'Ilmiyyah.

Umar Hilmi. (n.d.). Ithaf al-Akhlaf fi Ahkam al-Awqaf (Bestowing the Generations with the Provisions of Endowments). Translated from the Turkish language by Muhammad Kamil al-Ghizzi al-Halabi. Abdul Sattar Abu Ghuddah (Ed.). Jeddah, KSA: Dallah alBarakah Publications.
Ibn Mazah al-Bukhari, Abu al-Ma'ali Burhan al-Din Mahmood bin Ahmad bin Abdul Aziz. (1424H/2004). al-Muheet al-Burhani fi al-Figh al-Nu'maani (The All Encompassing on the Fiqh of al-Nauman (Abu Hanifah) by al-Burhani). Abdul Kareem Sami al-Jundi (Ed.). Beirut, Lebanon: Dar al-Kutub al-'Ilmiyyah.

Malik bin Anas (1406H/1985). al-Muwatta' (The Trodden Path). Muhammad Fu'ad Abdul Baqi (Ed.). Beirut, Lebanon: Dar Ihyaa' al-Turath al-'Arabi.

Muslim, Abu al-Hasan bin al-Hajjaj al-Qushairi (n.d.). Sahih Muslim (The Authentic Traditions by Muslim). Muhammad Fu'ad Abdul Baqi (Ed.). Beirut, Lebanon: Dar Ihya' al-Turath al-'Arabi.

The Islamic Research and Training Institute, Jeddah, General Secretariat of Endowments. (1425H/2004). Muntadaa Qadhaya al-Waqf al-Fiqhiyyah al-Awwal (The First Forum on the Islamic Jurisprudential (Fiqhi) Issues Regarding Endowments). Kuwait: The General Secretariat of Endowments Publications.

al-Mawsili, Abu Hafs Dhiyaa al-Din Umar bin Badr bin Saeed. (1407H). al-Mughni 'An al-Hifz wa alKitab (The Book Sufficing from Memorizing and Writing Ahadith). Published with its commentary "Junnat al-Murtab bi Naqd al-Mughni 'An al-Hifz wa al-Kitab" (The Shield of the Doubter: A Critical Commentary on The Book Sufficing from Memorizing and Writing Ahadith) by Abu Ishaq al-Huwaini. Beirut, Lebanon: Dar al-Kitab al-'Arabi.

$$
\begin{aligned}
& \text { العياشي الصادق فداد - كبير الباحثين - المعهد الإسلامي للبحوث والتدريب - البنك الإسلامي للتنمية }
\end{aligned}
$$

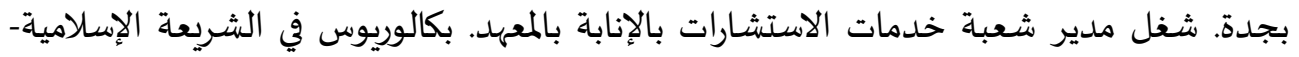

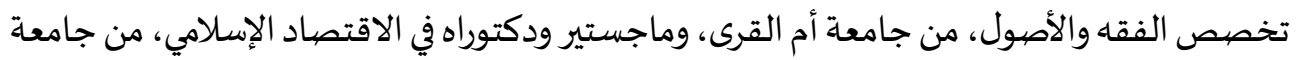

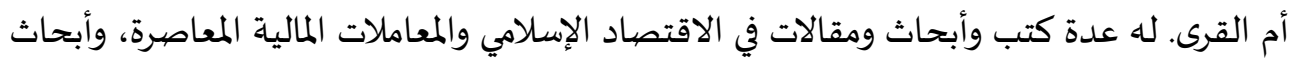

$$
\begin{aligned}
& \text { متخصصة في الزكاة والأوقاف. كما قام بإعداد حقائب علمية تدريبية في المعاملات المالية المعاصرة } \\
& \text { والزكاة والأوقاف. وأشرف على إعداد وتنفيذ برامج تدريبية في المصرفية الإسلامية ومؤسستي الزكاة } \\
& \text { والأوقاف. ومدرب معتمد، وعضو لجنة اعتماد المواد التدربيية والمدربين بالمجلس والمافي العام للبنوك }
\end{aligned}
$$

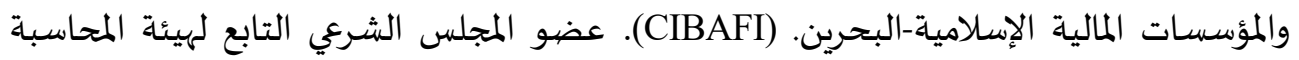

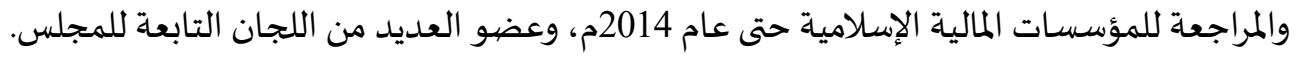

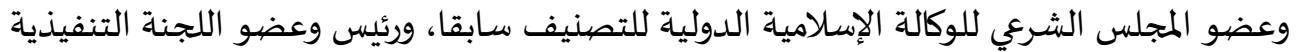

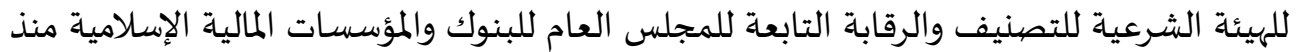




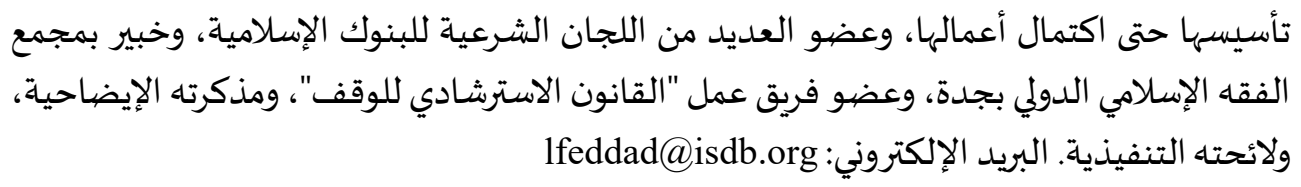

\title{
Stances with "Toward an Active Role of $A W A Q F$ in the life of Contemporary Muslim Societies" article by Muhamed Alarnaut
}

\author{
Layachi Feddad \\ Senior Shari'ah Specialist \\ Islamic Research and Training Institute, \\ Islamic Development Group, Jeddah, Saudi Arabia
}

\begin{abstract}
This paper discusses ideas and issues in the paper "Toward an Effective Role of Awqaf in the Life of Contemporary Muslim Societies" authored by Muhamed Alarnaut. The paper starts with the discussion with two important points: the first relating to the Prophet's hadiths on which the author relied to derive the permissibility of waqf in Shari'ah, and the second on the development of the investment of cash waqf in the Ottoman Caliphate. The paper also dealt with other important points like the investment of cash waqf on the interest basis.
\end{abstract}

KAUJIE Classification : E22, E23 